\author{
Jurnal E-Bis (Ekonomi-Bisnis) \\ Vol. 5 No.1 (2021) pp.31-44 \\ https://jurnal.politeknik-kebumen.ac.id/index.php/E-Bis \\ p-ISSN : 2580-2062 e-ISSN : 2622-3368
}

\title{
Pengaruh Kepuasan Kerja, PengembanganKarir terhadap Organizational Citizenship Behavior Dengan Komitmen Organisasi sebagai Variabel Intervening pada Karyawan PERURI
}

\author{
Vanya Chairiyah Fitri ${ }^{1 *}$,Dedi Purwana ${ }^{2}$, Ari Saptono ${ }^{3}$ \\ ${ }^{123}$ Magister Manajemen, Universitas Negeri Jakarta, Indonesia \\ *Email: vanyachai@gmail.com \\ Doi : https://doi.org/10.37339/jurnal e-bis.v5i1.448
}

Diterbitkan oleh Politeknik Dharma Patria Kebumen

\section{Info ArtikeI}

Diterima :

2021-02-18

Diperbaiki :

2021-02-22

Disetujui :

2021-03-10

\begin{abstract}
ABSTRAK
DaIam peneIitian ini diteIiti pengaruhkepuasan kerja, pengembangan karir terhadap organizational citizenship behavior dengan komitmen organisasi sebagai variabel intervening pada Karyawan PERURI. PeneIitian ini merupakan peneIitian kuantitatif dengan data primer, structuraI equation modeIing (sem) digunakan untuk menganaIisis data yang teIah didapat dariPERURI. Berdasarkan kriteria yang teIah ditentukan, peneIiti mendapatkan 200 data responden yang dianaIisis dengan menggunakan software AMOS. HasiI peneIitian ini menunjukkan bahwa kepuasan kerja, pengembangan karir dan komitmen berpengaruh terhadap OCB karyawan PERURI. Serta komitmen dapat memediasi pengaruh kepuasan kerja dan pengembangan karir terhadap kinerja karyawan.
\end{abstract}

Kata Kunci: Kepuasan Kerja, Pengembangan Karir, OCB

ABSTRACT

This research examines the effect of job satisfaction, career development on organizational citizenship behavior with organizational commitment as an intervening variable on PERURI employees. This research is a quantitative research with primary data, the equation modeling (sem) structure is used to analyze the data that has been obtained from PERURI. Based on the predetermined criteria, the researcher obtained 200 respondent data which were analyzed using AMOS software. The results of this research indicate that job satisfaction, career development and commitment affect the OCB of PERURI employees. And commitment can mediate the effect of job satisfaction and career development on employee performance.

Keywords:job satisfaction, career development, $O C B$ 


\section{PENDAHULUAN}

Perusahaan dituntut untuk mengikuti perkembangan di dalam menjalankan bisnis organisasinya.Saat ini era perkembangan teknologi digital semakin pesat, untuk mengikuti trend perkembangan zaman, paraperusahaan dituntut untuk mencanangkan sistem teknologi digitalisasi.Selain itu perusahaan juga di tuntut untuk maju dan berkembang agar dapat bertahan memperthanakan kondisi perusahaannya.Dimana setiap perusahaan berlomba-lomba untuk mendapatkan keuntungan yang maksimal agar bisnis perusahaan tersebut dapat tetap bertahan.

Salah satu perusahaan BUMN di Indonesia yaitu Perum Percetakan Uang Republik Indonesia (Peruri). Saat ini Peruri memiliki bisnis inti percetakan uang dan juga percetakan dokumen sekuriti lain seperti dokumen keimigrasian (paspor, visa, sticker legalisasi), pita cukai (label tanda pelunasanan pada rokok), sertifikat tanah, ijazah, dan dokumen lainnya. Peruri juga melebarkan bisnis perusahaan dengan membuka pasar baru di sejumlah negara Asia Pasifik.Salah satunya sukses menembus pasar Sri Lanka untuk pencetakan paspor, selain itu juga Peruri menembus pasar Nepal untuk pencetakan uang Negara Nepal serta Pita Cukai Rokok.

Seiring berkembangnya era digitalisasi, Peruri sedang menggarap Sektor New business yang dikembangkan untuk menghadapi perubahan yang begitu cepat di bidang pencetakan.Saat ini semakin berkembangnya cashless, Peruri dituntut untuk terus berinovasi dalam mengembangkan produk-produk unggulan terbaru.Peruri telah bertransformasi ke industri digital. Kini Peruri telah memiliki 3 (tiga) Produk digital yaitu Peruri Sign,Peruri Code, dan Peruri Trust dengan tujuan dapat memasuki pasar dan ikut berkembang dalam arus era digitalisasi.

Seperti diketahui bahwa pandemi covid-19 telah memberikan dampak yang sangat besar pada roda kehidupan.Bisnis-bisnis di Indonesia mengalami penurunan yang signifikan. Perusahan dituntut untuk menerapkan WorkFrom Home (WFH) guna melindungi para karyawan dan memutus rantai penyebaran Covid-19. Di sisi lain aktivitas kerja WFH memiliki dampak bagi proses bisnis perusahaan. Beberapa kendala yang muncul akibat perubahan pola kerja, pola komunikasi, administrasi, infrastruktur teknologi, surat menyurat hingga keamanan data. Kendala terbesar yang dialami selama kerja WFH yaitu proses administrasi dengan membubuhkan tanda tangan. Peruri melakukan inovasi digital yang membawa manfaat untuk membantu perusahaan-perusahaan untuk tetap mempertahankan kinerja perusahaan di tengah keterbatasan dengan memberikan layanan tanda tangan digital (Peruri Sign).

Layanan digital Peruri Sign memberikan efisiensi, kemudahan dan keamanan dalam menandatangani dokumen elektronik dan transaksi elektronik di mana dan kapan saja. Proses penerbitan atau pembubuhan tanda tangan digital sangat mudah dan cepat karena dapat dilakukan secara online namun tidak perlu diragukan untuk keamanannya karena Peruri menggunakan proses electronic know your customer (e-KYC) yang terintegrasi langsung ke data kependudukan. e-kyc memiliki hak akses mempermudah dan mempercepat proses validasi untuk penerbitan tanda tangan elektronik.

Berdasarkan hasil wawancara dengan bagian SDM dan data annual report, terjadi dinamika OCB organisasi yang terlihat pada nilai KPI karyawan PERURI. 
@Nama Lengkap ${ }^{1^{*}}$, Nama Lengkap ${ }^{2}$, Nama Lengkap ${ }^{3}$

Tabel 1.1 :Tingkat KPI (Key Performance Indicator)

\begin{tabular}{cccc} 
Tahun & 2017 & 2018 & 2019 \\
\hline Tingkat KPI & 88,74 & 88,02 & 77,31
\end{tabular}

Sumber: Data Annual Report (2019)

Berdasarkan data di atas terjadi penurunan tingkat KPI karyawan, pada tahun 2017 hingga 2018 mengalami penurunan dari 88,74 menjadi 88,02 dan kemudian menurun kembali di tahun 2019 menjadi 77,31. Karyawan yang memiliki sikap OCB maka akan mampu mendorong pencapaian tujuan perusahaan.Selain itu dengan budaya OCB dapat membantu perusahaan menjadi perusahaan terbaik dan bersaing di kelas internasional.

Faktor lain yang berperan dalam membentuk perilaku OCB adalah kepuasan kerja. Terlampir data hasil survei dalam 2 tahun terakhir sebagai berikut:

Tabel 1.2

Hasil Survei Kepuasan Kerja

\begin{tabular}{|c|c|c|}
\hline Dimensi & 2019 & 2018 \\
\hline Employee engagement & 7,63 & 7,20 \\
\hline Satisfaction Score & 6,95 & 6,77 \\
\hline Satisfaction Index & $80,5 \%$ & $76,8 \%$ \\
\hline Proporsi Pegawai pada level satisfied dan very satisfied & High & High \\
\hline
\end{tabular}

Sumber : Data annual report (2019)

Di sisi lain, fenomena juga tampak pada tingkat rotasi dan promosi karyawan yang terlihat pada tabel berikut ini:

Tabel 1.3

Tingkat Rotasi \& Promosi Karyawan

\begin{tabular}{cccc} 
Tahun & 2017 & 2018 & 2019 \\
\hline $\begin{array}{c}\text { Tingkat Rotasi } \\
\text { Karyawan }\end{array}$ & 370 & 347 & 285 \\
$\begin{array}{c}\text { Tingkat Promosi } \\
\text { Karyawan }\end{array}$ & 88 & 193 & 54
\end{tabular}

Sumber: Data Annual Report (2019)

Perurimemiliki program pengembangan karir salah satunya melalui kegiatan rotasi dan promosi.Di tahun 2019, Peruri telah melakukan rotasi terhadap 370 pegawai dan promosi terhadap 88 pegawai.Tingkat karyawan yang dipromosikan menurun dari tahun 2018 sejumlah 88, sebaliknya tingkat rotasi karyawan naik dari 347.Hal tersebut menjadi dinamika tersendiri bagi karyawan yang ingin mengembangkan diri.Faktanya karyawan lebih menginginkan promosi dibandingkan dengan rotasi yang cenderung membuat karyawan masuk ke dalam zona tidak nyaman.

Selain fenomena yang terjadi diatas, dalam penelitian-penelitian sebelumnya masih 
terdapat perbedaan hasil antara pengaruh komitmen organisasi dengan kepuasan kerja yang dilakukan oleh Yusra, Jullimursyidah, Sullaida (2017) dan Erwin (2017) menunjukan bahwa komitmen organisasi berpengaruh terhadap kepuasan kerja. Di sisi lain penelitian yang dilakukan oleh Abda Alif (2015) menunjukan hasil bahwa pengembangan karir tidak berpengaruh dengan kepuasan kerja. Selain itu terdapat penelitian lain yang dilakukan oleh Ni luh Putu Krisnha (2016) dan Erika, Hamidah (2018) yaitu pengaruh pengembangan karir terhadap organizational citizenship behavior. Penelitian tersebut menunjukan pengembangan karir berpengaruh positif dengan organizational citizenship behavior.

Berdasarkan latar belakang permasalahan, fenomena, dan research gap tersebut di atas maka penulis melakukan penelitian dengan judul "Pengaruh Komitmen Organisasi, Pengembangan Karir Terhadap Organizational Citizenship Behavior dengan Kepuasan Kerja sebagai Variabel Intervening pada Karyawan Peruri”..

\section{KAJIAN PUSTAKA}

\subsection{Manajemen SDM}

Manajemen sumber daya manusia merupakan suatu perencanaan, pengorganisasian, pengkoordinasian, pelaksanaan, dan pengawasan terhadap pengadaan, pengembangan, pemberian balas jasa, pengintegrasian, dan pemisahan tenaga kerja dalam rangka mencapai tujuan organisasi instansi (Mathis \& Jackson, 2002). Sesuai definisi tersebut Manajemen sumber daya manusia dapat dijelaskan sebagai suatu pengelolaan dan pendayagunaan sumber daya yang ada pada individu (karyawan).Pengelolaan dan pendayagunaan tersebut dikembangkan secara maksimal di dalam dunia kerja untuk mencapai tujuan organisasi dan pengembangan individu pegawai.Lebih lanjut (Noe, 2006) menjelaskan manajemen SDM merupakan ilmu dan seni mengatur hubungan dan peranan tenaga kerja agar efektif dan efisien membantu terwujudnya tujuan perusahaan, karyawan, dan masyarakat.

\subsection{Organizational Citizenship Behavior (OCB)}

Salah satu keberhasilan perusahaan terletak pada perilaku karyawan dalam perusahaan. Penelitian ini menyelidiki sejauh mana komitmen tim memoderasi hubungan antara kepuasan dan pengembangan kerja terhadap perilaku kewargaan organisasi (OCB)di antara karyawan dalam suatu organisasi. Selama beberapa dekade terakhir, perilaku kewargaan organisasi (OCB) telah menjadi konstruksi utama di bidangpsikologi dan manajemen dan mendapat banyak perhatian dalam literature (Dewi, 2017).Terdapat hampir 30 bentuk OCB yang berbeda.Perilaku kewarganegaraan organisasi menunjukkan perilaku individu secara sukarela dansecara agregat membantu fungsi organisasi agar terlaksana secara efektif dan efisien (Organ, 1988).Perilaku ini merupakan optimalisasi kerja sosial dalam organisasi dalam artian memberikan fleksibilitas yang dibutuhkan untuk mengatasi banyak hal yang tidak terduga dalam organisasi (Smith et al., 1983).

Definisi OCB telah diperluas untuk mencakup tidak hanya kategori altruisme (perilaku sukarela untuk membantu orang tertentu) dankepatuhan umum (kinerja yang cermat untuk kebaikan organisasi) tetapijuga kategori kesopanan, sportivitas, dan kebajikan (Podsakoff et al., 2000).Banyak peneliti memeriksa kategori kinerja OCB yang berkaitan dengan variabel 
kepribadian, dukungan organisasi, komitmen, motivasidasar(misalnya Borman et al., 2001; Organ, 1990), kepuasan kerja (Bateman dan Organ, 1983; Koys, 2001).Perkembangan penelitian tentang perilaku OCB dan masih dirasa kurang, peneliti mencoba mengambil variabel pengembangan karir yang masih jarang diteliti dengan OCB.

\subsection{Kepuasan Kerja}

Menurut Robbins (2009) tujuan utama selain bekerja umumnya adanya harapan yang diinginkan oleh karyawan yang jika harapan dapat tercapai maka akan timbul rasa kepuasan dalam bekerja. Kepuasan kerja didefinisikan dengan berbagai cara. Menurut Spector, kepuasan kerja adalah bagaimana perasaan orang tentang pekerjaan mereka dan berbagai aspek pekerjaan mereka (Spector, 1997). Bagi Nelson dan Quick (2006) kepuasan kerja adalah hal yang positif emosi atau kondisi menyenangkan yang timbul dari pekerjaan atau peringkat pengalaman kerja.Luthans (2008) memberikan definisi kepuasan kerja sebagai kondisi emosional atau menyenangkan yang positif appraisal atau pengalaman kerja seseorang.Sedangkan menurut Kepuasan kerja Luthans adalah hasil dari persepsi pekerja bagaimana pekerjaan mereka memberikan sesuatu yang dianggap penting.Apalagi menurut Robbins dan Judge (2007), kepuasan kerja juga perasaan positif tentang pekerjaan seseorang yang muncul dari penilaian karakternya.Penelitian ini menguji pengaruh langsung secara positif dan signifikan terkait dengan OCB.Kepuasan kerja memandang organisasi dapat memperlakukan karyawannya dengan adil, hal itu dapat memperkuat OCB karyawan. Di Sebaliknya, jika karyawan mempersepsikan organisasi tidak menunjukkan keadilan terhadap karyawan, dapat melemahkan OCB karyawan. Hubungan antara kepuasan kerja dan perilaku warga organisasi (OCB) telah diteliti oleh banyak peneliti dan mapan dalam literatur.Terdapat hubungan timbal balik antara kepuasan kerja dan OCB (Koys, 2001; Podsakoff et al., 1993).Kausalitas terarah tetap tidak pasti, tetapi banyak bukti menunjukkan bahwa terdapat hubungan kepuasan kerja dengan OCB (Podsakoff et al., 1993).

\subsection{Pengembangan Karir}

Karir merupakan seluruh pekerjaan yang dimiliki atau dilakukan oleh individu selama masa hidupnya.Karir merupakan pola dari pekerjaan dan sangat berhubungan dengan pengalaman (posisi, wewenang, keputusan dan interpretasi subjektif atas pekerjaan dan aktivitas selama masa kerja individu (Rivai dan Sagala, 2010). Semua pekerjaan atau jabatan yang di tangani atau di pegang selama kehidupan kerja seseorang.

Dalam konteks tujuan individu dan organisasi, pengembangan kariradalah proses meningkatkan kemampuan individudalam bekerja untuk mencapai karir yang diinginkan. Pengembangan karirbertujuan untuk mencocokkan tujuan individu dengan yang ketersediaanpeluang karir di dalam perusahaan untuk saat ini dan di masa depan.Komitmen dalam pengembangan karir dapat menunda keusangansumber daya manusia yang akan merugikan perusahaan. Ada tigapoin penting dalam pengembangan karir. Pertama, saat pertama kaliditerima sebagai pekerja, pengalaman di hari-hari awal bekerjasangat mempengaruhi pembentukan karakter dalam karirnya.Kedua, pada pertengahan karir (mid-career) yaitu periode dimana pekerja mulai memiliki tekanan dan tanggung jawab tidak sepertipertama kali diterima sebagai pekerja. Saat ini para pekerja menghadapi titik balik, ketika pekerja menghadapi 
stagnasi karir (karirstabil). Ketiga, periode menjelang dinas penuh waktu, di manapekerja menghadapi ketidakpastian karena kondisi ekonomi, sosial,hubungan psikologis dan interpersonal (Rivai, 2004).Dari sudut pandang organisasi, menurut Byars dan Rue(2008), pengembangan karir mempunyai tiga tujuan utama, yaitu:(1) Untuk memenuhi kebutuhan sumber daya manusia organisasi dijangka pendek dan jangka panjang, (2) untuk memberikan informasi yang lebih baikorganisasi dan individu tentang jalur karir potensial di dalamnyaorganisasi, dan (3) memanfaatkan sumber daya manusiaprogram yang telah ada dengan mengintegrasikan kegiatanmemilih, menugaskan, mengembangkan dan mengelola karir individudengan perencanaan organisasi. Beberapa peneliti telah menunjukkan pengembangan karir berpengaruh terhadap OCB seperti Rivai dan Sagala (2010) dan Naway \& Haris (2017).

\subsection{Komitmen Organisasi}

Komitmen dalam konteks OCB telah muncul sebagai topikdalam beberapa tahun terakhir.Karyawan membedakan antara komitmen dalamtim (komitmen tim) dan komitmen terhadap organisasi mereka (komitmen organisasi) (Bishop et al.,2005). Komitmen individu dalam organisasi kurang terlihat dibandingkantim dalam pekerjaan sehari-hari. Dengan kata lain, karyawan mungkin mengalami lebih sulit terhubungdengan organisasi daripada dengan tim, sedemikian rupa sehingga tingkat komitmen mereka terhadaporganisasi secara komparatif lebih rendah daripada komitmen mereka pada pekerjaan yang diarahkan tim (De Lara dan Rodriguez, 2007). Kaitannya dengan OCB Bishop dan Scott (2000), mempercayai bahwatim mandiri, dimana anggota bekerja sama secara erat secara berkelanjutan, sehingga berkembanghubungan timbal balik yang bermakna dan positif, dapat meningkatkan OCB dalam organisasi. Konsekuensinya, komitmen yang tinggi di antara anggota tim, dapat meningkatkan perilaku kewarganegaraan organisasi (OCB). Hubungan antara komitmen tim danperilaku kewarganegaraan organisasi sebelumnya telah terbukti kuat dansignifikan (Bishop dan Scott, 2000; Bishop et al., 2000; De Lara dan Rodriguez, 2007).

\subsection{Kerangka Kerja}

Berdasarkan teori diatas, untuk menggambarkan hubungan antara variabelkomitmen, pengembangan karir, kepuasan dan OCB dapat digambarkan daIam modeI penelitian sebagai berikut: 


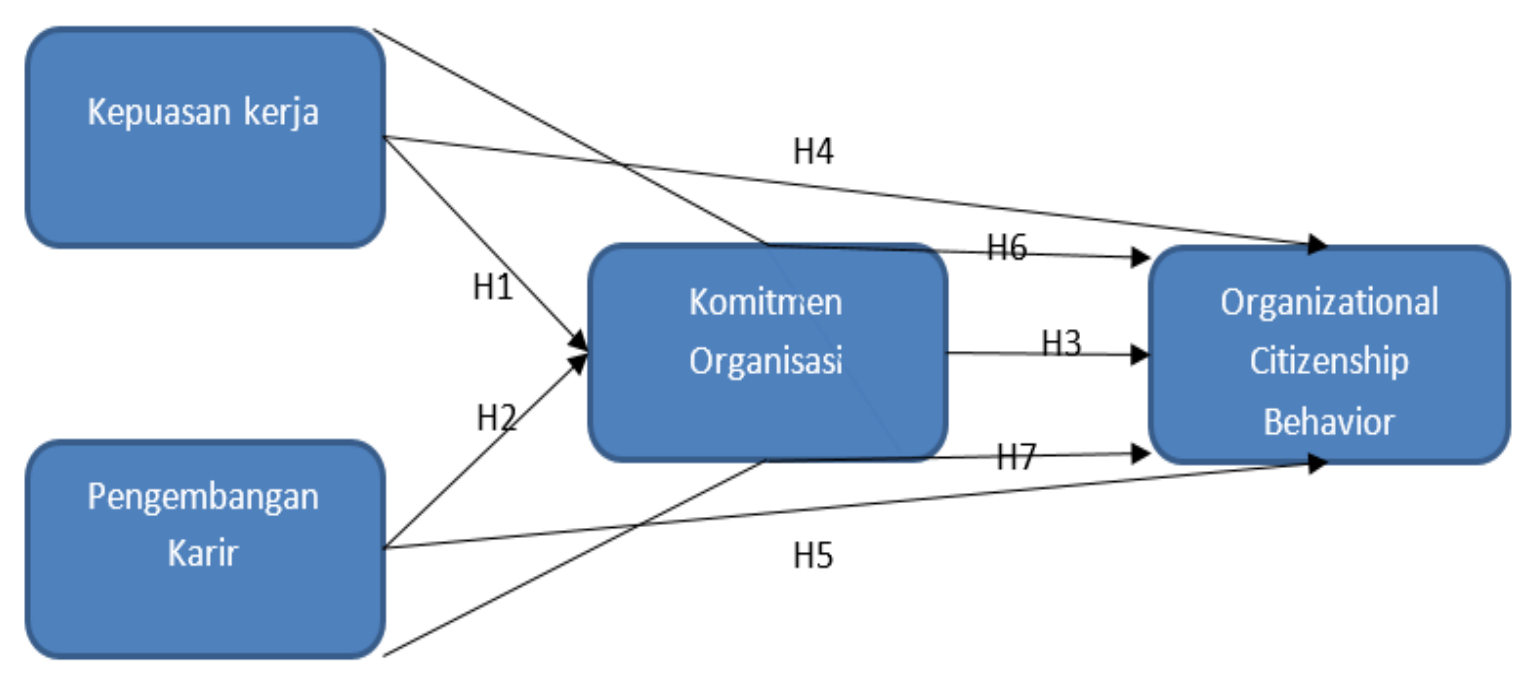

Gambar 2.1.Hubungan komitmen, pengembangan karir, kepuasan dan OCB.

\section{METODE}

Konstruksi yang digunakan untuk penelitian ini diadaptasi dari literatur sebelumnya.Penelitian ini merupakan penelitian kuantitatif dengan melakukan studi pendahuluan sebelumnya.Dari hasil wawancara didapatkan data pra studi bahwa terjadi dinamika OCB yang disebabkan oleh kepuasan kerja, pengembangan karir dan komitmen organisasi. Data primer digunakan melalui kuesioner dengan skala likert lima poin digunakan untuk mengukur komitmen organisasi, kepuasan kerja, pengembangan organisasi dan perilaku kewarganegaraan organisasi. Item dalam instrumen survei diadaptasi dari penelitian terdahulu. Skala yang digunakan untuk penelitian ini berkisar dari 1 =sangat tidak setuju sampai $5=$ sangat setuju.200 responden digunakan dalam penelitian sesuai dengan data internal perusahaan dengan metode purposive sampling.Dalam penelitian ini OCB merupakan variabel dependen, komitmen variabel mediasi, kepuasan dan pengembangan karir sebagai variabel independen.

\section{HASIL DAN PEMBAHASAN}

\subsection{Hasil}

Berdasarkan hasiI AMOS 20 dan SPSS versi 25 pada pengujian sebelumnya, kemudian diteIaah Iebih Ianjut untuk menerima atau menoIak hipotesis yang terdapat daIam peneIitian ini, maka dapat dijeIaskan pada hasiI uji hipotesis sebagai berikut ini: 


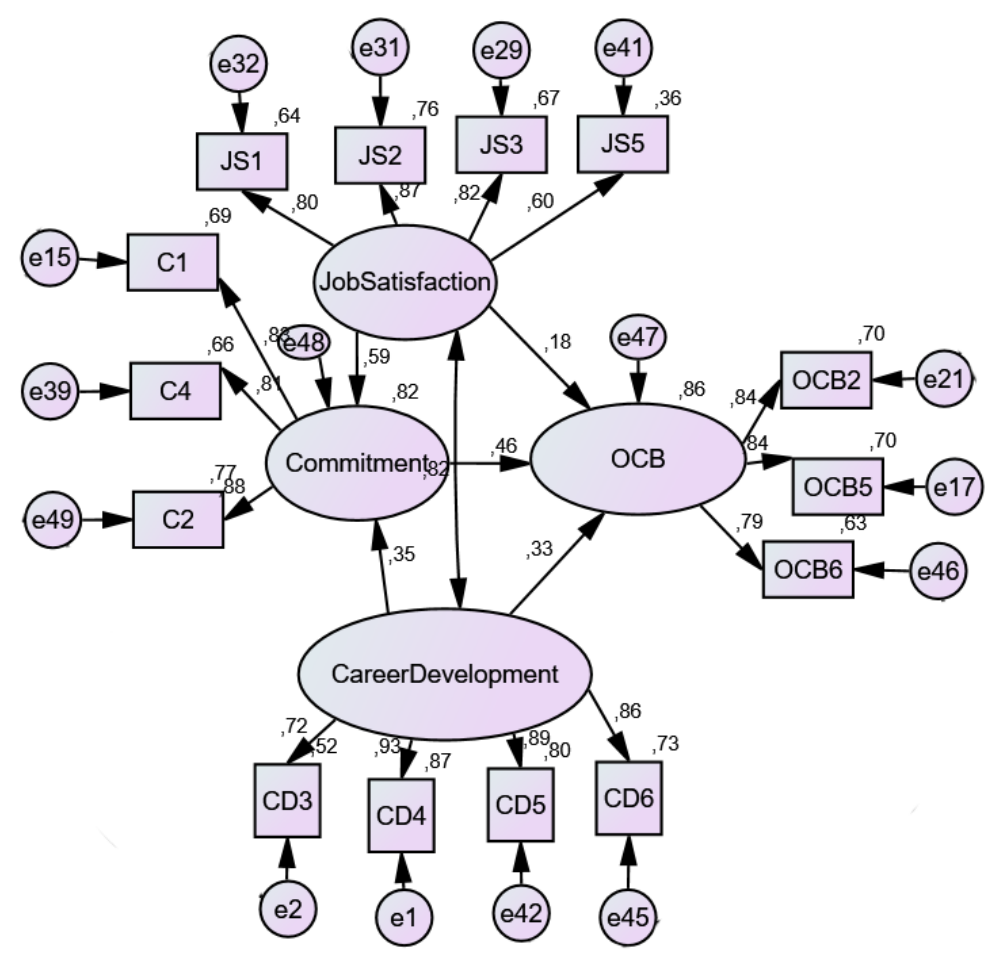

Chi-Square $=81,321 ; \mathrm{df}=63 ; \mathrm{Prob}=, 060 ; \mathrm{cmin} / \mathrm{df}=1,291$

;RMR=,027 ; $\mathrm{AGFI}=, 913 ; \mathrm{GFI}=, 948 ; \mathrm{CFI}=, 992 ; \mathrm{TLI}=, 988$

Sesuai dengan Hayes (2008) dan berdasarkan Gambar 4.8 di atas, tampak kriteria Goodness of Fit (GOF) belum tercapai, sehingga perlu melakukan modifikasi model dengan melihat nilai Modification Indices (M.I). Penghapusan indikator atas saran nilai Modification Indicesakan menurunkan nilai chi-square (x2) sehingga membuat model menjadi fit.

Hasil Goodness of Fit Model Struktural Modifikasi

\begin{tabular}{llcc}
\multicolumn{1}{c}{ Kriteria } & \multicolumn{1}{c}{ Cut-off Value } & Hasil Uji Model & Keterangan \\
Chi-Square $\left(\mathrm{x}^{2}\right)$ & lihat probabilitas $(\mathrm{P})>0,05$ & 81,321 & good fit \\
CMIN/DF & $\leq 5($ reasonable $) \leq 2($ fit $)$ & 1,291 & good fit \\
P (probabilitas) & $\geq 0,05$ & 0,060 & good fit \\
RMSEA & $\leq 0,08$ & 0,023 & good fit \\
GFI & $\geq 0,90$ & 0,948 & good fit \\
AGFI & $\geq 0,90$ & 0,913 & good fit \\
TLI & $\geq 0,90$ & 0,988 & good fit \\
CFI & $\geq 0,90$ & 0,992 & good fit \\
\hline
\end{tabular}

Sumber : Hasil Pengolahan Data, 2020

\begin{tabular}{|c|c|c|c|c|}
\hline \multirow[b]{2}{*}{ Hipotesis } & \multicolumn{2}{|c|}{ Hasil Analisis Model Struktural } & \multirow[b]{2}{*}{$\mathrm{P}$} & \multirow[b]{2}{*}{ Kesimpulan } \\
\hline & Jalur & C.R. & & \\
\hline H1 & Commitment<--- JobSatisfaction & 6,280 & $* * *$ & Diterima \\
\hline $\mathrm{H} 2$ & Commitment<-CareerDevelopment & 4,010 & $* * *$ & Diterima \\
\hline $\mathrm{H} 3$ & OCB<--- Commitment & 3,424 & $* * *$ & Diterima \\
\hline
\end{tabular}


@Nama Lengkap ${ }^{1^{*}}$, Nama Lengkap ${ }^{2}$, Nama Lengkap ${ }^{3}$

$\begin{array}{lllll}\text { H4 } & \text { OCB<--- JobSatisfaction } & 3,483 & * * * & \text { Diterima } \\ \text { H5 } & \text { OCB<--- CareerDevelopment } & 3,426 & * * * & \text { Diterima }\end{array}$

\begin{tabular}{clcc} 
Hipotesis & \multicolumn{1}{c}{ Jalur Mediasi } & P value & Kesimpulan \\
\hline \multirow{2}{*}{ H6 } & $\begin{array}{l}\text { CareerDevelopment---> } \\
\text { Commitment --->OCB }\end{array}$ & 0,008 & Diterima \\
H7 & $\begin{array}{l}\text { JobSatisfaction ---> } \\
\text { Commitment --->OCB }\end{array}$ & 0,282 & Diterima \\
& $\begin{array}{l}\text { Sumber : Hasil Pengolahan Data, 2020 } \\
\end{array}$ &
\end{tabular}

\subsection{Pembahasan}

\section{a. Pengaruh kepuasan kerja Terhadap komitmen}

Hasil pengujian diatas dapat disintesiskan bahwa terdapat pengaruh kepuasan kerja terhadap komitmen terbukti dengan nilai CR 6,280, dengan nilai tersebut terbukti bahwa CR $>1,96$ dan nilai $\mathrm{P}=* * *$ serta melebihi nilai $\mathrm{P}$ dengan signifikasi 5\% $(\mathrm{P}<0,05)$. Kepuasan karyawan Peruri berpengaruh terhadap komitmen organisasi.Hasil penelitian ini mendapatkan temuan bahwa kepuasan kerja berpengaruh terhadap komitmen organisasi.Pelaksanaan kepuasan karir menciptakan penguatan komitmen organisasi serta menjadi momentum ke atas untuk meningkatkan sikap karyawan, puas dan perbaikan berkelanjutan Yusra (2017).Dari sudut pandang praktis, manajer dalam organisasi dapat mengimplementasikan peningkatan kepuasan mulai dari aspek fisiologis hingga aktualisasi diri sehingga menghasilkan komitmen tim. Pelaksanaan program kepuasan kerja sebagai bagian dari strategi peningkatan organisasi dapat berpengaruh positif, hasil penelitian ini sesuai dengan pernyataan Pingkan et.al., (2017).

\section{b. Pengaruh pengembangan karirterhadap komitmen}

Hasil pengujian diatas dapat disintesiskan bahwa terdapat pengaruh pengembangan karir terhadap komitmen terbukti dengan nilai CR 4,010, dengan nilai tersebut terbukti bahwa CR $>1,96$ dan nilai $\mathrm{P}=* * *$ serta melebihi nilai $\mathrm{P}$ dengan signifikasi 5\% ( $<<0,05)$. Pengembangan karir karyawan Peruri berpengaruh terhadap komitmen.Hasil penelitian ini mendapatkan temuan bahwa pengembangan karir berpengaruh terhadap komitmen organisasi. Pelaksanaan pengembangan karir menciptakan penguatan komitmen organisasi serta menjadi momentum ke atas untuk meningkatkan sikap karyawan,komitmen dan perbaikan berkelanjutan (Bahri et.al., 2017). Dari sudut pandang praktis, manajer dalam organisasi dapat mengimplementasikanpeningkatan pengembangan karir menghasilkan komitmen tim. Pelaksanaan program pengembangan sebagai bagian dari strategi pengembangan organisasi dapat berpengaruh positif, hasil penelitian ini sesuai dengan pernyataan Lisdiani (2017).

\section{c. Pengaruh komitmenberpengaruh terhadap OCB}

Hasil pengujian diatas dapat disintesiskan bahwa terdapat pengaruh komitmen terhadap OCB terbukti dengan nilai CR 3,424, dengan nilai tersebut terbukti bahwa CR >1,96 dan nilai P $=* * *$ serta melebihi nilai $\mathrm{P}$ dengan signifikasi $5 \%(\mathrm{P}<0,05)$.Hasil penelitian ini memberikan wawasan mengenai situasi di mana komitmen karyawan menghasilkan perubahan sikap perilaku ke arah positif(Baron, 2000). Jika anggota tim belum memiliki komitmen dalam tim dan 
organisasi mereka, mereka tidak dapat berperilaku OCB dan berkinerja lebih tinggi untuk tim tersebut (Budiyanto,2013). Pekerjaan yang memiliki komitmen tinggi didapat dari hubungan rekan kerja yang lebih baik pada gilirannya dapat mengarah ke yang lebih tinggi tingkat OCBtim, dan pada akhirnya meningkatkan keseluruhan perilaku kewarganegaraan organisasi dalam organisasi (Rahayu 2017). Temuan bahwa komitmen untuk satu tim meningkatkan kemungkinan terlibat dalam perilaku kewarganegaraan organisasi untuk karyawan dengan komitmen yang lebih tinggi memberikan wawasan penting tentang manfaat potensial komitmen terhadap OCB secara keseluruhan.

\section{d. Pengaruh kepuasan terhadap OCB}

Hasil pengujian diatas dapat disintesiskan bahwa terdapat pengaruh kepuasan kerja terhadap OCB terbukti dengan nilai CR 3,483, dengan nilai tersebut terbukti bahwa CR >1,96 dan nilai $\mathrm{P}=* * *$ serta melebihi nilai $\mathrm{P}$ dengan signifikasi $5 \%(\mathrm{P}<0,05)$. Hasil perhitungan statistik dalam penelitian ini mendukung hipotesis pengaruh kepuasan kerja terhadap OCB. Hasil penelitian menunjukkan bahwa peningkatan kepuasan kerja akan berdampak pada peningkatan OCB. Begitu pula jika kepuasan kerja menurun, ini akan berdampak pada penurunan OCB. Kepuasan kerja adalah kebutuhan setiap individu dalam bekerja, begitu pun organisasi, sehingga perlu ditingkatkan oleh setiap organisasi.Hasil ini sesuai dengan Ristiana (2013) Udayani, et.al., (2015) Alif (2015). Kepuasan kerja mengacu dengan kondisi di mana seseorang merasakan perasaan menyenangkan yang muncul sebagai hasil dari penilaian pekerjaan atau pengalaman kerja yang terjadi di PT tempat kerja, khususnya yang berkaitan dengan aspek pekerjaan tersebut yang dapat memuaskan karyawan seperti pekerjaan itu sendiri, promosi, pengawasan, mitra bisnis, kondisi kerja, tantangan, dan komunikasi. Ketika aspek kerja dipenuhi dengan baik dan secara memadai, maka karyawan akan merasa senang dan puas. Pada gilirannya akan merangsang karyawan untuk melakukan tindakan di luar peran yang jelas memberikan kontribusi positif bagi organisasi, atau umumnya dikenal OCB. Ketika karyawan memperoleh dari kepuasan pada berbagai aspek pekerjaan seperti pekerjaan itu sendiri seperti promosi, pengawasan, mitra, kondisi kerja, tantangan, dan komunikasi, karyawan dapat meningkatkan untuk berpikir, bertindak dan bersikap altruistik, sportivitas, sopan santun, dan sehat untuk kepentingan organisasi.

\section{e. Pengaruh pengembangan karir terhadap OCB}

Hasil pengujian diatas dapat disintesiskan bahwa terdapat pengaruh pengembangan karir terhadap OCB terbukti dengan nilai CR 3,426 dengan nilai tersebut terbukti bahwa CR >1,96 dan nilai $\mathrm{P}=* * *$ serta melebihi nilai $\mathrm{P}$ dengan signifikasi $5 \%(\mathrm{P}<0,05)$. Sehingga OCB karyawan Peruri dipengaruhi oleh Pengembangan karir.Hasil perhitungan statistik dalam penelitian ini mendukung hipotesis pengaruh pengembangan karir terhadap OCB. Hasil penelitian menunjukkan bahwa peningkatan pengembangan karir akan berdampak pada peningkatan OCB. Begitu pula jika pengembangan karir menurun, akan berdampak pada penurunan OCB. Pengembangan karir merupakan kebutuhan setiap individu dalam bekerja, begitu pun organisasi, sehingga perlu ditingkatkan oleh setiap organisasi.Hasil ini sesuai denganErika (2018) dan Alif (2015). Pengembangan karir berkaitan dengan prestasi kerja karyawan, kesetiaan terhadap organisasi, mentor dan sponsor, dukungan para bawahan dan kesempatan untuk bertumbuh. Pada gilirannya akan merangsang karyawan untuk melakukan tindakan di luar peran yang jelas memberikan kontribusi positif bagi organisasi, atau umumnya 
dikenal OCB. Ketika karyawan memperoleh pengembangan karir pada berbagai aspek pekerjaan seperti pekerjaan itu sendiri dapat meningkatkan untuk berpikir, bertindak dan bersikap altruistik, sportivitas, sopan santun, dan sehat untuk kepentingan organisasi.

\section{f. Pengaruh kepuasan terhadap OCB karyawan dengan komitmen sebagai mediasi}

Hasil pengujian diatas dapat disintesiskan bahwakomitmen dapat memediasi pengaruh kepuasanterhadap OCB terbukti dengan nilai $\mathrm{P}=0,008$ sesuai dengan $(\mathrm{P} \neq 0)$.Sehingga komitmen memediasi pengaruh kepuasan kerja terhadap OCB.Hal tersebut didukung oleh hasil penelitian sebelumnya yang dilakukan oleh Muayanah (2016) dan Haryono (2016) yang menyatakan bahwa kepuasan kerja yang dimediasi oleh komitmen memiliki pengaruh signifikan positif terhadap OCB. Dalam penelitiannya, Budiastri (2016) mendapatkan nilai $\mathrm{P}$ sebesar $* * *(<0,05)$ sehingga hipotesisnya diterima. Jika dalam pekerjaan yang ditingkatkan kepuasan kerja yang didapat dari hubungan rekan kerja pada gilirannya dapat mengarah ke tingkat komitmen timyang lebih tinggi, dan pada akhirnya meningkatkan keseluruhan perilaku kewarganegaraan organisasi (OCB) dalam organisasi mereka (Muayanah, 2016) dan (Haryono, 2016). Penemuan ini juga menunjukkan bahwa komitmen untuk satu timmemediasi pengaruh kepuasan terhadap perilaku kewarganegaraan organisasi dalam hal ini karyawan dengan kepuasan kerja yang lebih tinggi memberikan kekuatan dalam komitmen yang akan berdampak pada perilaku OCB organisasi.

\section{g. Pengaruh pengembangan diri terhadap OCB karyawan dengan komitmen sebagai mediasi}

Hasil pengujian diatas dapat disintesiskan bahwakomitmen dapat memediasi pengaruh pengembangan karirterhadap OCB terbukti dengan nilai $\mathrm{P}=0,282$ sesuai dengan $(\mathrm{P} \neq 0)$. Sehingga komitmen memediasi pengaruh pengembangan karirterhadap OCB.Hal ini sesuaipenelitian sebelumnya yang dilakukan oleh Organ (2003), pengaruh antara kepuasan kerja dan komitmen terbukti signifikan, kemudian pengaruh antara komitmen tim dan OCB juga signifikan. Yang terpenting, pengaruh antara kepuasan kerja dan perilaku kewargaan organisasional (OCB) dimediasi oleh komitmen tim, sehingga komitmen menjadi lebih kuat ketika kepuasan kerja tinggi dan kemudian akan meningkatkan OCB. Temuan bahwa kepuasan kerja berpengaruh terhadap komitmen organisasi dan kemudian memperkuat OCB menjelaskan bahwa pelaksanaan kepuasan kerja dapat menciptakan penguatan komitmen tim dan memperjelas untuk meningkatkan sikap karyawan dalam perbaikan berkelanjutan (Yusra, 2016).Jika dalam pekerjaan yang ditingkatkan pengembangan karir yang terencana pada gilirannya dapat mengarah ke tingkat komitmen tim yang lebih tinggi, dan pada akhirnya meningkatkan keseluruhan perilaku kewarganegaraan organisasi (OCB) dalam organisasi mereka (Yusra, 2016). Penemuan ini juga menunjukkan bahwa komitmen untuk satu tim memediasi pengaruh pengembangan karir terhadap perilaku kewarganegaraan organisasi. Dalam hal ini karyawan dengan pengembangan karir yang jelas memberikan kekuatan dalam komitmen yang akan berdampak pada perilaku OCB organisasi.Karyawan dapat lebih semangat dan memiliki wawasan yang luas sehingga dapat lebih komitmen dan berperilaku kewarganegaraan organisasi (OCB).

\section{KESIMPULAN}

Kesimpulan dari artikeI ini adaIah:

1. Hasil pengujian Hipotesis 1, kepuasan kerja memiliki pengaruh signifikan positif terhadap komitmen. Artinya semakin baik kepuasan kerja yang diberikan oleh Peruri maka akan 
meningkatkan komitmen pada para karyawan. Oleh karena itu, H1 diterima. Hasil ini didukung oleh teori dari Kotler (2016) dan hasil pengujian dari penelitian sebelumnya oleh Waluya (2019), Khoironi (2018), Ginantra (2017), Djumarno (2017), dan Budiastri (2016) yang menyatakan bahwa ada pengaruh signifikan positif dari kepuasan terhadap komitmen.

2. Hasil pengujian Hipotesis 2, pengembangan karir memiliki pengaruh signifikan positif terhadap komitmen. Artinya semakin baik pengembangan karir yang diberikan Peruri maka akan meningkatkan komitmen pada karyawan. Oleh karena itu, H2 diterima. Hasil ini didukung oleh teori dari Kotler (dalam Gaol, 2016) dan hasil pengujian dari penelitian sebelumnya oleh Sitanggang (2019), Waluya (2019), Wantara (2019), Hoe (2018), Khoironi (2018), Djumarno (2018), Ginantra (2017), Djumarno (2017), dan Budiastri (2016) yang menyatakan bahwa ada pengaruh signifikan positif dari pengembangan karir terhadap komitmen.

3. Hasil pengujian Hipotesis 3, komitmen memiliki pengaruh signifikan positif terhadap OCB. Artinya semakin tinggi tingkat komitmen karyawan maka akan meningkatkan OCB karyawan Peruri. Oleh karena itu, H3 diterima. Hasil ini didukung oleh teori dari Tjiptono (dalam Gaol, 2016) dan hasil pengujian dari penelitian sebelumnya oleh Sitanggang (2019), Maisya (2019), Wantara (2019), Hoe (2018), Khoironi (2018), Djumarno (2018), Darmawan (2018), Erwin (2017), Chiguvi (2017), dan Djumarno (2017) yang menyatakan bahwa ada pengaruh signifikan positif dari komitmen terhadap OCB.

4. Hasil pengujian Hipotesis 4, kepuasan kerja memiliki pengaruh signifikan positif terhadap OCB. Artinya semakin tinggi tingkat kepuasan kerja karyawan maka akan meningkatkan OCB karyawan Peruri. Oleh karena itu, H4 diterima. Hasil ini didukung oleh hasil pengujian dari penelitian sebelumnya oleh Sitanggang (2019), Khoironi (2018), dan Djumarno (2017, 2018) yang menyatakan bahwa ada pengaruh signifikan positif dari kepuasan kerja terhadap OCB.

5. Hasil pengujian Hipotesis 5, pengembangan karir memiliki pengaruh signifikan positif terhadap OCB. Artinya semakin tinggi pengembangan karir karyawan maka akan meningkatkan OCB karyawan Peruri. Oleh karena itu, H5 diterima. Hasil ini didukung oleh hasil pengujian dari penelitian sebelumnya oleh Khoironi (2018), Darmawan (2018), dan Djumarno (2017) yang menyatakan bahwa ada pengaruh signifikan positif dari pengembangan karir terhadap OCB.

6. Hasil pengujian Hipotesis 6 , kepuasan kerja memiliki pengaruh signifikan positif terhadap OCB yang dimediasi oleh komitmen. Artinya komitmen yang dibangun oleh Peruri juga secara tidak langsung mempengaruhi tingkat OCB yang disebabkan oleh tingkat kepuasan kerja karyawan Peruri. Oleh karena itu, H6 diterima. Hasil ini didukung oleh hasil penelitian sebelumnya oleh Khoironi (2018) dan Budiastri (2016) yang menyatakan bahwa kepuasan kerja yang dimediasi oleh komitmen memiliki pengaruh signifikan positif terhadap OCB.

7. Hasil pengujian Hipotesis 7, pengembangan karir memiliki pengaruh signifikan positif terhadap OCB yang dimediasi oleh komitmen. Artinya komitmen yang dibangun oleh Peruri juga secara tidak langsung mempengaruhi tingkat OCB yang disebabkan oleh tingkat pengembangan karir karyawan Peruri.. Oleh karena itu, H7 diterima. Hasil ini didukung oleh teori dari Santon (dalam Gaol, 2016) dan penelitian sebelumnya yang dilakukan oleh Sitangga (2019), Khoironi (2018), Djumarno (2018), dan Budiastri (2016) pengembangan karir yang dimediasi oleh komitmen memiliki pengaruh signifikan positif terhadap OCB.

\section{REFERENSI}

Aisyah, L. N., \& Wartini, S. (2016). Pengaruh Kepemimpinan Transformasional dan Kualitas Kehidupan Kerja pada Organizational Citizenship Behavior melalui Komitmen 
Organisasional. Management Analysis Journal, 5(3).

Angelo, K., \& Kreitner, R. (2001).Organizational Behavior. International Edition.

Alwi, S. (2001).Manajemen sumber daya manusia strategi keunggulan kompetitif. BPFE, yogyakarta.

Danendra, A. N. B., \& Mujiati, N. W. (2016). Pengaruh Motivasi, Kompensasi Dan Komitmen Organisasional Terhadap Organizational Citizenship Behavior (OCB). E-Jurnal Manajemen, 5(10).

Diputra, A. A., \& Rahyuda, A. G. R. (2015).Pengaruh Kepemimpinan Transformasional dan Kepuasan Kerja terhadap Komitmen Organisasi dan Organizational Citizenship Behavior Guru SD Saraswati 4 Denpasar. E-Jurnal Manajemen, 5(1).

Fred, L. (2001). Organizational Behavior.Ninth.

Gunawan, R. (2016). Pengaruh Kepemimpinan Transformasional Terhadap Organizational Citizenship Behavior (OCB) Pada PT First Marchinery Tradeco Cabang Surabaya. Agora, 4(1), 60-66.

Handoko, T. H. (2009). Manajemen, Cetakan Duapuluh. Penerbit BPPE.

Hasibuan, H. (2012). Manajemen sumber daya manusia, Edisi Revisi. PT Bumi Aksara. Jakarta.

Kurniawan, A. (2015). Pengaruh komitmen organisasi terhadap organizational citizenship behavior (OCB) PT X Bandung. Jurnal Manajemen Maranatha, 15(1).

Mangkunegara, A. A. P. (2016). Manajemen sumber daya manusia perusahaan.PT. Remaja Rosdakarya.

Mathis, R. L., \& Jackson, J. H. (2002). Manajemen Sumber Daya Manusia Buku 2. Jakarta: Salemba Empat.

Noe.(2006). Human Resource Management.5th Edition. Mc Graw Hill

Northouse, P. G. (2013). Leadership: theory and practice SAGE Publications. Inc.,, 383-405.

Organ, D. W., Podsakoff, P. M., \& SB, M. SB 2006. Organizational Citizenship Behavior: Its Nature, Antecedents, and Consequences. BOOK REVIEW ADVISORY, 59, 205.

Pradhiptya, A. R. (2013). Pengaruh Kepuasan Kerja Terhadap Organizational Citizenship Behaviour (Ocb) Dengan Mediasi Komitmen Organisasional. Jurnal Ilmu Manajemen, 1(1), 342-542.

Raja, A. S., \& Palanichamy, P. (2011).Leadership styles and its impact on organizational commitment. Asia Pacific business review, 7(3), 167-175. 
Ribke Widyanto, Jennie Suhandono Lau., Endo Wijaya Kartika. (2013). Pengaruh Kepuasan Kerja Terhadap Organizational Citicenship Behavior (OCB) Melalui Komitmen Organisasional Karyawan Cleaning Service di ISS Surabaya.Jurnal Hospitality dan Manajemen Jasa.Vol. 1, No 1, Hal. 1-15

Robbins, Stephen P., dan Judge, Timothy A. (2014). Perilaku Organisasi. Jakarta: Salemba Empat.

Rusdiyanto, W., \& Riani, A. L. (2015).Pengaruh Kepemimpinan Transformasional dan Transaksional pada Organizational Citizenship Behavior dengan Kepuasan Kerja sebagai Pemediasi. Jurnal Economia, 11(2), 161-168.

Sopiah.(2008). Perilaku Organisasional.Yogyakarta : C.V Andi Offset.

Steers, R.M, Porter, L.W. (1983). Motivation and Work Behavior, New York: Academic Press.

Tampi, G. S. (2013). Kepemimpinan dan kompensasi pengaruhnya terhadap kinerja karyawan dan dampaknya terhadap organization citizenship behavior. Jurnal EMBA: Jurnal Riset Ekonomi, Manajemen, Bisnis dan Akuntansi, 1(3).

Wahyudi, A. (2008). Membangun Komitmen Organisasional Untuk Meningkatkan Kinerja dan Daya Sasing Organisasi. Joglo, Vol. 20. No.1

Widayanti, R., \& Farida, E. (2016). Pengaruh kepuasan kerja dan komitmen organisasi terhadap organizational citizenship behavior (Study pada karyawan pemerintah kabupaten malang). Jurnal Aplikasi Manajemen, 14(4), 697-704.

Wiener, Y. (1982). Commitment in Organizations : A normative view. Academy of Management Review.No. 7.Hal. 418-428

Yukl A. Gary (1998), Kepemimpinan Dalam Organisasi. Jakarta: Prenhallindo 